\title{
Ocorrência de CymMV em orquídeas do gênero Arundina no Estado do Rio de Janeiro ${ }^{(1)}$
}

\author{
EVERALDO HANS STUDT KLEIN ${ }^{(2)}$ e PAULO SERGIO TORRES BRIOSO(3)
}

\begin{abstract}
RESUMO
Plantas da espécie Arundina bambusifolia Lindl. foram coletadas no município de Teresópolis, RJ, com sintomas típicos de presença de vírus: manchas nas flores e nas folhas, encarquilhamento de botões florais e aborto de novas brotações. $\mathrm{O}$ presente trabalho tem por objetivo registrar a ocorrência desta doença no Estado do Rio de Janeiro, em uma espécie de grande importância para o mercado de paisagismo na atualidade e identificar o seu patógeno. Testes sorológicos confirmaram a presença do Cymbidium mosaic virus infectando essas plantas.

Palavras-chave: Potexvirus, orquídea-bambu.
\end{abstract}

\section{ABSTRACT \\ Occurrence of CymMV in orchids of the genus Arundina in the State of Rio de Janeiro.}

Plants of Arundina bambusifolia Lindl. were collected in Teresópolis, RJ, exhibiting typical symptoms associated with the presence of viruses: necrotic spots on flowers, stems and leaves, malformation of the flower buds and abortion of new canes. This work aims to report the occurrence of this disease in the State of Rio de Janeiro, affecting an orchid species of great importance for the market of landscaping and floriculture at the present time. Serologic tests confirmed the presence of the Cymbidium mosaic virus infecting these plants.

Keywords: Potexvirus, Bamboo orchid

As orquídeas da espécie Arundina bambusifolia Lindl. são muito populares, bastante comum em jardins residenciais, tanto na Capital como no interior do Estado do Rio de Janeiro, provavelmente em virtude de sua fácil propagação, que se dá por divisão de touceiras ou mudas formadas espontaneamente nos ramos, o que tornou o seu valor comercial bastante acessível. Conhecida como orquídea-bambu, a Arundina é terrestre, ereta, semiherbácea, rizomatosa, entouceirada, originária do Sudeste Asiático (WATANABE, 2002), com 1,20-2,00 m de altura, de ramagem e florescimento extremamente decorativo. Inflorescências com flores branco-lilases e labelo roxo são formadas o ano todo, principalmente na primavera e no verão, e são cultivadas a meia-sombra ou a pleno sol, em jardineiras e renques, acompanhando muros, muretas e paredes, ou em grupos formando conjuntos isolados (LORENZI e SOUZA, 2001). Pelo fato de produzir grande quantidade de flores praticamente o ano todo, o que é uma exceção na família Orchidaceae, essa planta se tornou muito importante para o mercado de paisagismo e plantas ornamentais.

A planta infectada foi coletada pelo autor em outubro de 2007, em um jardim residencial de Teresópolis, região serrana do Estado do Rio de Janeiro, apresentando sintomas de reduzido tamanho das flores com descontinuidade da coloração natural das sépalas e pétalas, mosaico e manchas necróticas nas folhas e hastes florais. Trazida ao Laboratório Oficial de Diagnóstico Fitossanitário, área de Fitopatologia, do Departamento de Fitopatologia e Entomologia - Instituto de Biologia, da Universidade Federal Rural do Rio de Janeiro, diagnosticou-se por meio da realização de teste sorológico (imunocromatográfico) da Empresa Agdia, conforme recomendação do fabricante, a presença do Cymbidium mosaic virus (CymMV) infectando a planta (Figura 1). Esse kit diagnóstico que foi utilizado acusa a presença dos vírus Cymbidium mosaic virus (CymMV) e Odontoglossum ringspot virus (ORSV), tanto em infecções simples como em infecções duplas. O resultado obtido determinou a infecção simples de CymMV. A possibilidade de existir a presença de outro vírus, também comum em orquídeas, o Orchid fleck virus (OFV), infectando a referida planta foi descartada com resultados negativos obtidos em teste biológico (inoculação de extratos foliares de orquídea em folhas expandidas de Chenopodium amaranticolor Coste \& Reyn.).

O CymMV é comum em orquídeas, cuja presença se dá em cerca de 25 gêneros, incluindo os mais

(1) Parte da Dissertação de Mestrado do primeiro autor. Recebido para publicação em 11/08/2008 e aprovado em 04/08/2008. ( $\left.{ }^{2}\right)$ Mestrando do Programa de Pós-graduação em Fitossanidade e Biotecnologia Aplicada - Universidade Federal Rural do Rio de Janeiro (UFRRJ). Caixa Postal 74585, 23851-970 Seropédica (RJ). Bolsista CAPES. E-mail: studt.everaldo@uol.com.br

$\left({ }^{3}\right)$ Laboratório Oficial de Diagnóstico Fitossanitário, área de Fitopatologia, Departamento de Fitopatologia e Entomologia, Instituto de Biologia UFRRJ. Bolsista CNPq. E-mail: brioso@bighost.com.br. 
comerciais, como Cattleya, Cymbidium, Dendrobium, Miltonia, Oncidium e Sophronittis (GIORIA et al., 2003). O CymMV é capaz de induzir uma diversidade de sintomas em plantas infectadas, dependendo de fatores ambientais, idade do tecido vegetal e genótipo da amostra (PASQUAL et al., 2005). O sintoma mais comum é o mosaico, podendo ocorrer clareamento das nervuras foliares e pequena redução no número e tamanho das flores. Sintomas severos incluem o aparecimento de lesões anelares ou irregulares, cloróticas ou necróticas nas folhas (GIORIA et al., 2003), necrose e/ou descontinuidade da coloração natural das sépalas e pétalas (figura 1). Esse vírus pode infectar uma planta, sem afetar sua produtividade ou vigor, por muitos anos (COOKE, 1999), o que dificulta a identificação com base apenas nos sintomas visuais.

O CymMV pertence ao gênero Potexvirus, caracterizado por apresentar partículas alongadas e flexuosas, de comprimento de $480 \mathrm{~nm}$ e diâmetro de 13 $\mathrm{nm}$. Apresenta virions estáveis, altamente infectivos e sem envelope (ICTVdB, 2007). É um vírus de transmissão exclusivamente mecânica, ou por contato, com a ausência de insetos vetores (FRANCKI, 1984). É comumente disseminado por ferramentas de poda contaminadas (FREITAS-ASTUA et al., 1999).

A sua presença nessas plantas de valor ornamental torna-se desastrosa pela perda da beleza de todos os órgãos da planta, como folhas e pseudobulbos e, em especial, pelos sintomas causados nas flores, que vão desde o aborto de botões florais, sua malformação, formação de flores com tamanho reduzido e regiões com mosaico e descoloração das cores naturais e até a presença de tecidos necrosados (FREITAS-ASTUA et al., 1999). Nas plantas coletadas, verificou-se também a morte de brotações novas, lesões necróticas em hastes florais e malformação das flores. A doença é bastante séria em razão da grande utilização dessa planta em paisagismo na atualidade e pelo fato de a doença não possuir cura ou tratamento. $O$ presente relato ainda sugere a inexperiência de alguns produtores ao permitirem que plantas infectadas sejam conduzidas ao mercado.

Para evitar a disseminação do agente causal dessa doença, tanto os orquidófilos e funcionários de orquidários, como outros produtores de plantas ornamentais que se aventuram a propagar esta espécie, devem estar sempre com equipamento mínimo de proteção para impedir a contaminação das plantas: luvas de látex e um spray com solução desinfetante para limpar as mãos e ferramentas na realização das práticas culturais (poda, troca de vaso e limpeza) de uma planta e outra. Pode-se utilizar produtos à base de quaternários de amônio e hipoclorito de sódio. As ferramentas de corte devem ser imersas por dois minutos nesses produtos antes de serem utilizadas em uma nova planta. O uso de pequenos maçaricos portáteis, assim como o bico de Bunsen, também tem sido uma solução prática e rápida para a esterilização dessas ferramentas, já que o CymMV é permanentemente destruído por exposição a temperaturas acima de $150^{\circ} \mathrm{C}$ por alguns segundos (COOKE, 1999). A aquisição de matrizes saudáveis e a destruição de plantas infectadas também são fundamentais para se evitar novas contaminações (KLEIN, 2004).

\section{REFERÊNCIAS}

COOKE, R.B. Doenças das Orquídeas: parte II - vírus. Disponível em < http://www.orquidario.org/palestras/ palestra02.htm $>$ Acesso em 12/12/2007.

FRANCKI, R.I.B. Plant viruses online descriptions and lists from the VIDE Database. Cymbidium mosaic potexvirus, 1984. Disponível em: <http:// image.fs.uidaho.edu/vide/descr274.htm $>$ Acesso em 29/ $11 / 2007$.

FREITAS-ASTUA, J.; REZENDE, J.A.M.; KITAJIMA, E.W. Incidence of orchid viruses in the State of São Paulo, Brazil. Fitopatologia Brasileira, Brasília, v.24, n.2, p.125-130, 1999.

GIORIA, R.; SOUZA, A.P.; PEDRAZZOLI, D.S.; KITAJIMA, E.W.; KIMATI, H.; REZENDE, J.A.M.; VENDRAMIM, J.D.R; PARRA, J.R.P. Doenças e pragas que atacam as orquídeas. Taubaté : Editora Brasil Orquídeas, 2003. 64p.

ICTVdB - The Universal Virus Database International Commitee of Taxonomy of Viruses version 4. BüchenOsmond, C. (Ed), Columbia University, New York, USA ICTVdB Management (2006). 00.056.0.01.007. Cymbidium mosaic virus. Disponível em <http:// www.ncbi.nlm.nih.gov/ICTVdb/ICTVdB/ 00.056.0.01.007.htm> Acesso em 29/11/2007

KLEIN, E.H.S. Manejo de Doenças em Orquidários Comerciais do Estado do Rio de Janeiro. Monografia realizada para conclusão do curso Latu-sensu em "Manejo de Doenças de Plantas", 2004. Lavras; UFLA, 2004. 31p.

LORENZI, H.; SOUZA, H.M. Plantas Ornamentais do Brasil: arbustivas, herbáceas e trepadeiras, 3. ed. Nova Odessa : Instituto Plantarum, 2001. 1120p.

PASQUAL, M.; ARAÚJO, A.G.; RODRIGUES, V.A.; OLIVEIRA, A.C. Cultivo de Orquídeas. Informe Agropecuário, Belo Horizonte, v.26, n.227, p.85-94, 2005.

WATANABE, D. Orquídeas: manual de cultivo. São Paulo : AOSP - Associação Orquidófila de São Paulo, 2002. 296p. 

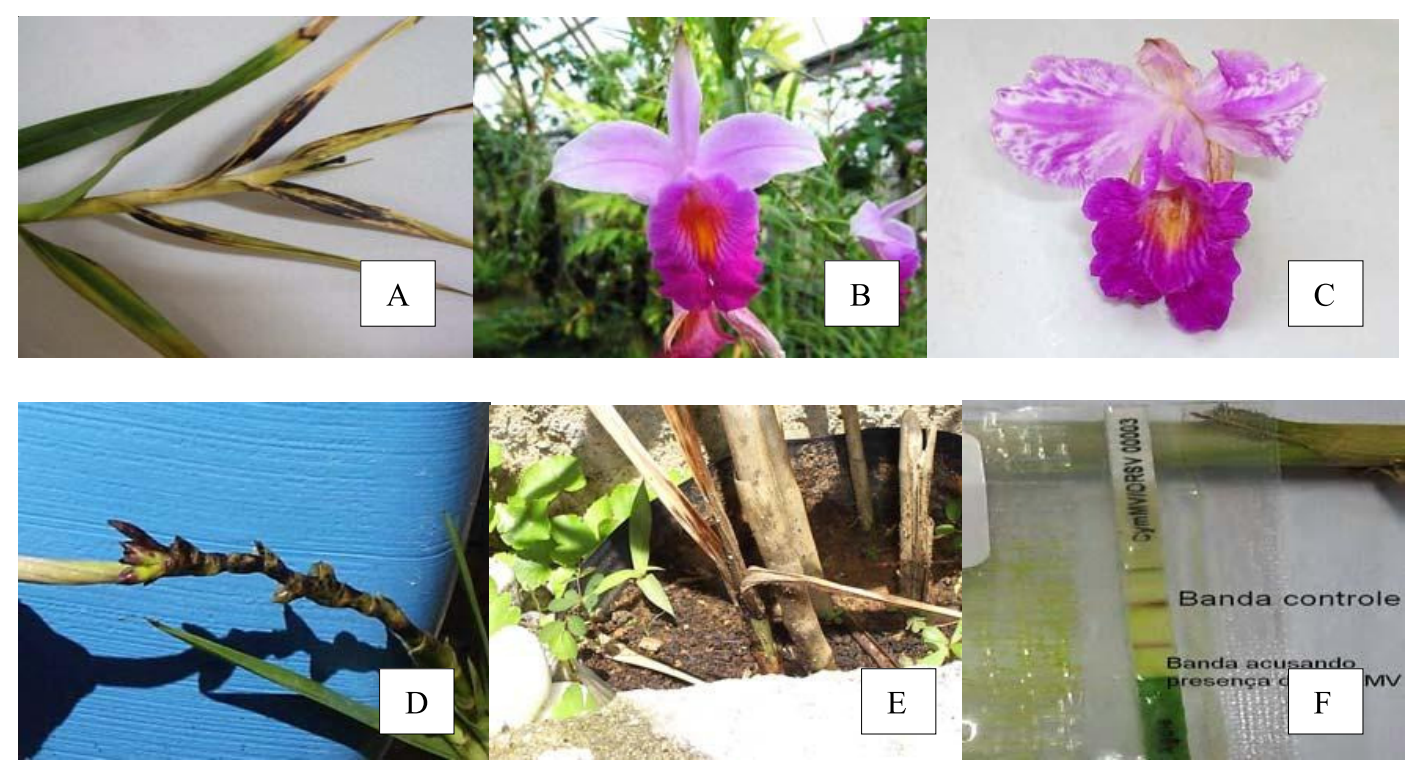

Figura 1. Orquídea Arundina bambusifolia: folhas novas apresentando lesões necróticas (A); Flor de uma planta sadia (B); Flor apresentando malformação e mosaico (C); Lesões necróticas em haste floral (D); Aborto de novas brotações (E); Teste imunocromatográfico (Empresa Agdia) para o Cymbidium mosaic virus (F).

Figure 1. Arundina bambusifolia orchid: New leaves exhibiting necrotic spots (A); Flower of a healthy plant (B); Flower exhibiting malformation and mosaic (C); Necrotic spots of the flower buds (D); Abortion of new canes $(E)$; Immunochromatographic test (Agdia Inc.) detecting Cymbidium mosaic virus $(F)$. 